\title{
POTENTIAL AND USE OF THE GOOGLENET ANN FOR THE PURPOSES OF INLAND WATER SHIPS CLASSIFICATION
}

\author{
Katarzyna Bobkowska ${ }^{1,2}$ \\ Izabela Bodus-Olkowska ${ }^{3}$ \\ ${ }^{1}$ Gdańsk University of Technology, Poland \\ ${ }^{2}$ Marine Technology Sp. z o.o., Gdynia, Poland \\ ${ }^{3}$ Maritime University of Szczecin, Poland
}

\begin{abstract}
This article presents an analysis of the possibilities of using the pre-degraded GoogLeNet artificial neural network to classify inland vessels. Inland water authorities monitor the intensity of the vessels via CCTV. Such classification seems to be an improvement in their statutory tasks. The automatic classification of the inland vessels from video recording is a one of the main objectives of the Automatic Ship Recognition and Identification (SHREC) project. The image repository for the training purposes consists about 6,000 images of different categories of the vessels. Some images were gathered from internet websites, and some were collected by the project's video cameras. The GoogLeNet network was trained and tested using 11 variants. These variants assumed modifications of image sets representing (e.g., change in the number of classes, change of class types, initial reconstruction of images, removal of images of insufficient quality). The final result of the classification quality was $83.6 \%$. The newly obtained neural network can be an extension and a component of a comprehensive geoinformatics system for vessel recognition.
\end{abstract}

Keywords: ship classification, image classification, geoinformatics, artificial intelligence, artificial neural network

\section{INTRODUCTION}

In terms of vessel traffic, there are several techniques and methods for monitoring water areas. The most popular are AIS (Automatic Identification System) and radar. These two systems are often supported by radio communication and video surveillance (CCTV). All these components make up the RIS (River Information Service) or VTS (Vessel Traffic System) system, where the operator can easily identify the vessel and acquire all information about its voyage, crew members, shipowner or cargo. The water traffic observation system is well organized in the scope of large sea vessels and inland cargo ships, mainly due to the fact that these vessels are covered by legal equipment requirements. However, there is a huge problem in the field of small inland boats, such as motor or rowing boats, small sailing yachts and pleasure crafts. In general, they are not equipped with AIS, radar or VHF systems. Many of them do not even require registration in the relevant registers. Given the growing interest in pleasure water tourism, there is a need to support the monitoring through a recognition and identifying system dedicated to small boats and their approximate location.

The Automatic Ship Recognition and Identification (SHREC) project aims to develop a system for detecting, recognizing and identifying small boats based on video monitoring from CCTV cameras located in strategic points of the water area such as bridges and marinas [1]. It will cover the inland water areas in Szczecin-Swinoujscie harbor located in the northwest of Poland and will provide support for the RIS-ODRA system (River Information Service). While the detection of a vessel itself is simple, its recognition and identification are more complex tasks. For this purpose, the SHREC project assumes the use of artificial neural networks and searches for an available tool that can be implemented with the SHREC system. The project is funded by the Polish LIDER NCBiR program. 
Recognition of vessel types based on images is not a new issue. Specialists in the field of image processing and analysis as well as computer vision have been dealing with this problem for many years. However, there is no solution that can be directly implemented with the SHREC system. First, solutions based on the analysis of satellite imagery can be indicated [2-4]. However, these methods are not suitable for the recognition of small ships and real-time data analysis. The key to the SHREC project is a solution that will allow real-time recognition based on images collected using standard digital cameras at a short distance (e.g., a camera located near to a water reservoir or river) to recognize the vessel.

Systems that monitor vessel movement (such as the River Information Service of Lower Oder) [5] are equipped with video cameras. Unfortunately, often the video stream is not analyzed using artificial intelligence methods but by manual analysis performed by the operator. Yet, such systems can be a huge source of data to train neural networks.

By analyzing the literature and available knowledge on the use of computer vision when analyzing a video stream of vessels from cameras, three issues can be identified. The first of these is the issue of vessel detection [6-8]. The next issue is the detection and recognition of text on the vessel (e.g., International Maritime Organization (IMO) number and registration) [9]. The last is the issue related to vessel recognition. These issues are the most important in the context of the research carried out in this study. Researchers dealing with this topic most often utilize convolutional neural networks (CNNs) for classifications. There are also analyses involving the use of simple classifiers for the purposes of the task [10]. In this case, the classification method used was k-nearest neighbors $(\mathrm{kNN})$. For the purpose of selecting the features, an image analysis was performed with the use of the Hough transform. Thanks to the tested approach, it was possible to detect sailing yachts and separate them from other vessels. The described achievement is not sufficient for the purposes of the classification of all vessels that are the subject of the SHREC system analyses. An example of using more complex classifiers and neural networks is the publication [11]. In this case, convolutional neural networks VGG19 were used. Scientists classified five classes and obtained an F1-score of $70 \%$. Another study [12] used deep convolutional neural networks and gnostic fields. The authors of this publication obtained classification quality results of more than $85 \%$ for images taken during the day due to combining images in the visible and infrared spectrum. A multi-task learning framework has also been proposed by scientists [13]. They used deep feature embedding, coarse-grained classification and fine-grained classification. The above-mentioned solutions do not meet the key conditions that should be met by the SHREC system component aimed at the classification of ships:

- obtaining high values of the classification quality based on the visual image,

- carrying out the classification for objects that are subject to classification in the SHREC project,

- minimizing the speed of the classification process - by default, the classification should take place in real time.
Therefore, it was decided to verify another available solution, which is the verification of one of the most popular neural networks which is easily available, widely used and tested, achieving high values of classification quality for objects based on images. For this reason, it was decided for the purposes of the project that the pretrained GoogLeNet network would be tested.

The aim of this study is to analyze the potential development and use of the most popular neural network for image classification - GoogLeNet - for the classification of vessels on inland waterways. GoogLeNet is a pretrained convolutional neural network that is 22 layers deep. This net is commonly used, for example, with Chinese handwriting [14], scene recognition [15], autonomous driving [16], feature tracking [17], artifact removal, classification [18], domain adaptation [19] and medicine [20].

\section{MATERIALS AND METHODS}

\section{DATA COLLECTION}

For the initial stage of the task, an analysis of the categories of vessels that the SHREC system would deal with in the classification process was made. The following ship types were selected:

1. kayak, pedalo, rowing boat - small units powered by muscle power;

2. small boat, motorboat - small units with an outboard internal combustion engine, usually without a built-in cabin or without a cabin and a low superstructure;

3. motor yacht - mechanically propelled boat, with an outboard or permanent engine, higher superstructure and a cabin up to approximately $10 \mathrm{~m}$ in length;

4. sailing yacht with a mast - yacht with a single sail, with or without a cabin;

5. sailing yacht with a mast down;

6. large motor yacht - power boat, with fixed engine, higher superstructure, a cabin, over $10 \mathrm{~m}$ in length, luxury;

7. sailing ship - sailing vessel with more than one mast;

8. barge - large inland waterway vessel with cargo holds for general cargo, bulk or liquid cargo;

9. inland pusher - inland waterway vessel used for "pushing" barges without a mechanical drive, the whole creating a pushed set;

10. pushed convoy - inland pusher with a set of inland barges;

11. water services - police, WOPR (Volunteer Water Rescue Service), border guards; usually these are smaller vessels, serving in the port and in the coastal zone of the territory of a given country; they are distinguished by appropriate colors and descriptions of the service they represent;

12. small ship - small conventional ship defined as a ship below 24 m length, ships with cargo holds for the transport of bulk and general cargo, ships for the transport of liquid materials/chemicals, ships for the transport of bulky cargo; 
13. medium ship - conventional ships up to $120 \mathrm{~m}$ long, ships with holds for the transport of bulk and general cargo, ships for the transport of liquid materials/chemicals, ships for the transport of bulky goods;

14. large ship - conventional ships of over $120 \mathrm{~m}$ in length, ships with holds for the transport of bulk and general cargo, ships for the transport of liquid materials/chemicals, ships for the transport of bulky goods;

15. navy ship - military ships, properly marked and in gray colors;

16. special vessel - measuring vessel, dredger, icebreaker; vessels designed for maintaining the navigation path and works in port: measuring vessel - small vessels; dredger vessel with visible dredging equipment/pipes; tug - small vessel with visible low stern side;

17. passenger ship - sea or inland ship for the transport of people;

18. special purpose service ships (e.g., hydrographic, security, fire, telecommunications, customs, sanitary, school, pilot, icebreakers, rescue);

19. fishing vessels - small vessels for fishing at sea, often with fishing gear/frame at the rear;

20. ships of historical value;

21. other ships.

It was determined from which angles the unit's view was assumed. Angles from $0^{\circ}$ to $315^{\circ}$ were set with a $45^{\circ}$ division clockwise. The next step was to collect photos, which were gathered from two sources:

- photos gathered from the internet;

- photos obtained from video recording in the area of the Szczecin-Swinoujscie port complex.

The first source consisted of 200 photos for each of the 21 categories of vessels, which gives a total of 4,200 photos. As far as possible, attempts were made to collect photos representing vessels from different angles. The second catalog, which was created from video registrations of the 2018 measurement campaign, showed that the previous categories of vessels were too detailed for the inland basin of Szczecin-Swinoujscie harbor. Taking into account the depth of the water area together with the shipment possibilities of the port of Szczecin itself, some ships do not appear at all, due to too much draft of the ship. Therefore, the number of vessel categories was reduced from 21 to 6 :

- barge - combining inland barges, pushers and pushed sets;

- special purpose service ships;

- motor yacht, with motorboat;

- passenger ship;

- sailing yacht;

- other.

Figures 1 and 2 present sample images of vessel categories.

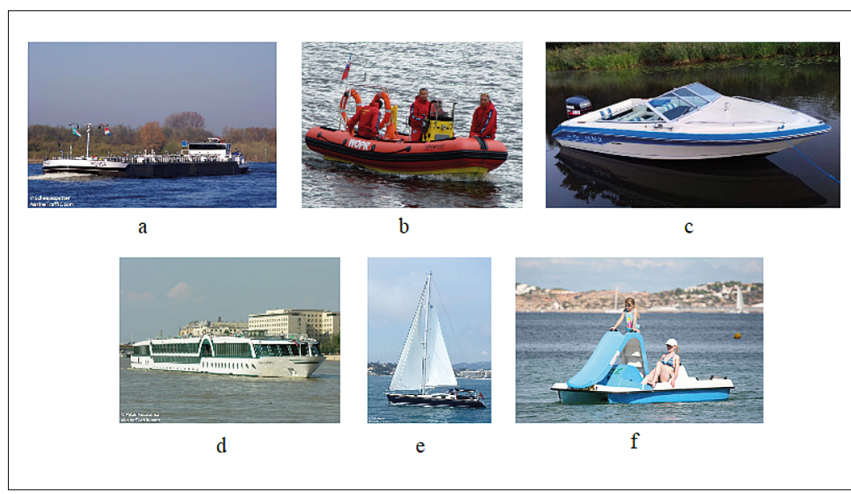

Fig. 1. Examples of images included in the classes in the case of a collection obtained from the internet (a., barge; b., special purpose service ships; c., motor yacht with motorboat; $d$., passenger ship; e., sailing yacht; $f$., other)

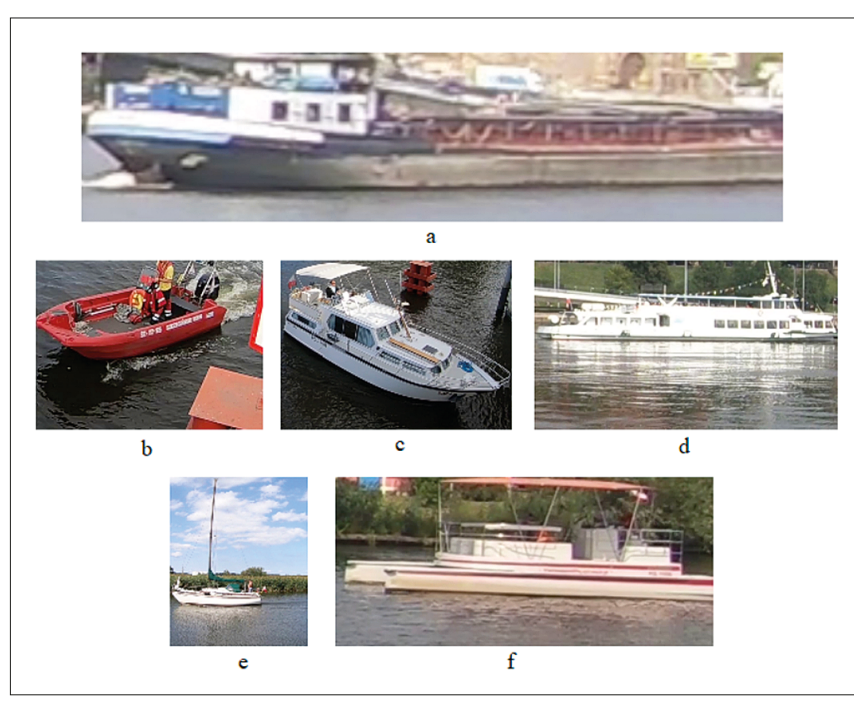

Fig. 2. Examples of images included in the classes in the case of a set of images obtained from video recordings (a., barge; b., special purpose service ships; c., motor yacht with motorboat; $d$., passenger ship; e., sailing yacht; f., other)

Finally, from the video registration, about 6,000 images were obtained. Both catalogs were then filtered for the quality of the photo itself, the repeatability of the vessel and the size of the ship in the photo. The filtered catalogs were then used to train GoogLeNet.

\section{METHODS AND TOOLS}

The key tool used to achieve the goals of this research was Matlab software, with the following toolboxes: Deep Learning Toolbox Model for GoogLeNet Network, Deep Learning Toolbox, Image Processing Toolbox, Computer Vision Toolbox. The use of this numerical computing environment for the needs of analysis related to artificial intelligence and machine learning is very popular today, in particular for the classification and recognition of objects based on photos $[21,22]$ there is a growing interest in the use of non-contact techniques to automate this process. Machine learning techniques, such as artificial neural networks, support vector machines (SVMs. Matlab is a tool that enables the use of ready-made components (functions, scripts, etc.), but it is also possible to edit and create additional components from 
scratch. We focused on verifying the potential to use a readymade tool - pretrained GoogLeNet deep convolutional neural network (GoogLeNet CNN) - for vessel recognition.

\section{PRETRAINED GOOGLENET DEEP CONVOLUTIONAL NEURAL NETWORK (GOOGLENET CNN)}

GoogLeNet CNN is a pretrained network with 22 layers. This network facilitates the classification of images in 1,000 object categories (there is no category related to vessel classification) in the ImageNet dataset. The Matlab environment gives the opportunity to train GoogLeNet CNN based on new datasets, as was done in this study.

\section{ARTIFICIAL NEURAL NETWORK TRAINING AND CLASSIFICATION OF IMAGES PROCESS}

The commonly used transfer training was used to retrain the convolutional neural network for the new set of images in this study. This process does not involve training the network from the very beginning but uses a pretrained network as the starting point. Some pretrained layers can be reused when training a new set. This saves a lot of time to develop learned functions for new collections and allow the network to be trained with a smaller number of images. Figure 3 presents the process used for this study, which was based on a defined algorithm of process that is described in detail on the software manufacturer's website. [23]

The process, which was aimed at developing a scheme for the classification of vessels, focused on testing one developed algorithm for network retraining and classification. This process is presented below (Figure 3). The selection of the appropriate dataset for network training involved the development of several different sets of images that represented different classes.

The process of training and testing began with image preprocessing. As a way of selecting the best algorithm for image preprocessing, the assessment of the quality of the classification based on the confusion matrix was chosen. In a situation where the quality of classification for a given set decreased, another way of developing the set was sought. As quality increased, it was verified whether there was still an optimal alternative, testing another variant. All changes that were made to the dataset were named variants and are described in Section 3 (Results). Variant testing was performed until the desired classification quality value was reached (above $82 \%$ ).

\section{RESULTS}

For each variant of the dataset, the GoogLeNet network was trained from the beginning and the classification was carried out. The scheme of division of chosen variants is presented in Figure 4. Table 1 presents information on the selection of individual variants, a description of the set and a comment on the results obtained.

The work began with the classes, i.e., barge, other, special purpose service ships, motor yacht, passenger ship and sailing yacht. These classes were selected because of the place where the recordings were made - these vessels sail on inland waters. Successively, changes to class variants were carried out to verify the recognition potential among more classes. Collections of sets of different class variants have been developed. There are collections that contain more detailed classes of recreational facilities such as a kayak, rowing boat or pedalo. Some collections only contain information on the general classification of floating objects or collections combining several classes of objects, such as pushed convoy and barges combined into one class. The collections are as follow:

- Z1 - barge, other, special purpose service ships, motor yacht, passenger ship, sailing yacht;

- Z2 - barge, other, special purpose service ships, kayak, motor yacht, passenger ship, sailing yacht;

- Z3 - barge, other, special purpose service ships, kayak, passenger ship, sailing yacht, small motor yacht, large

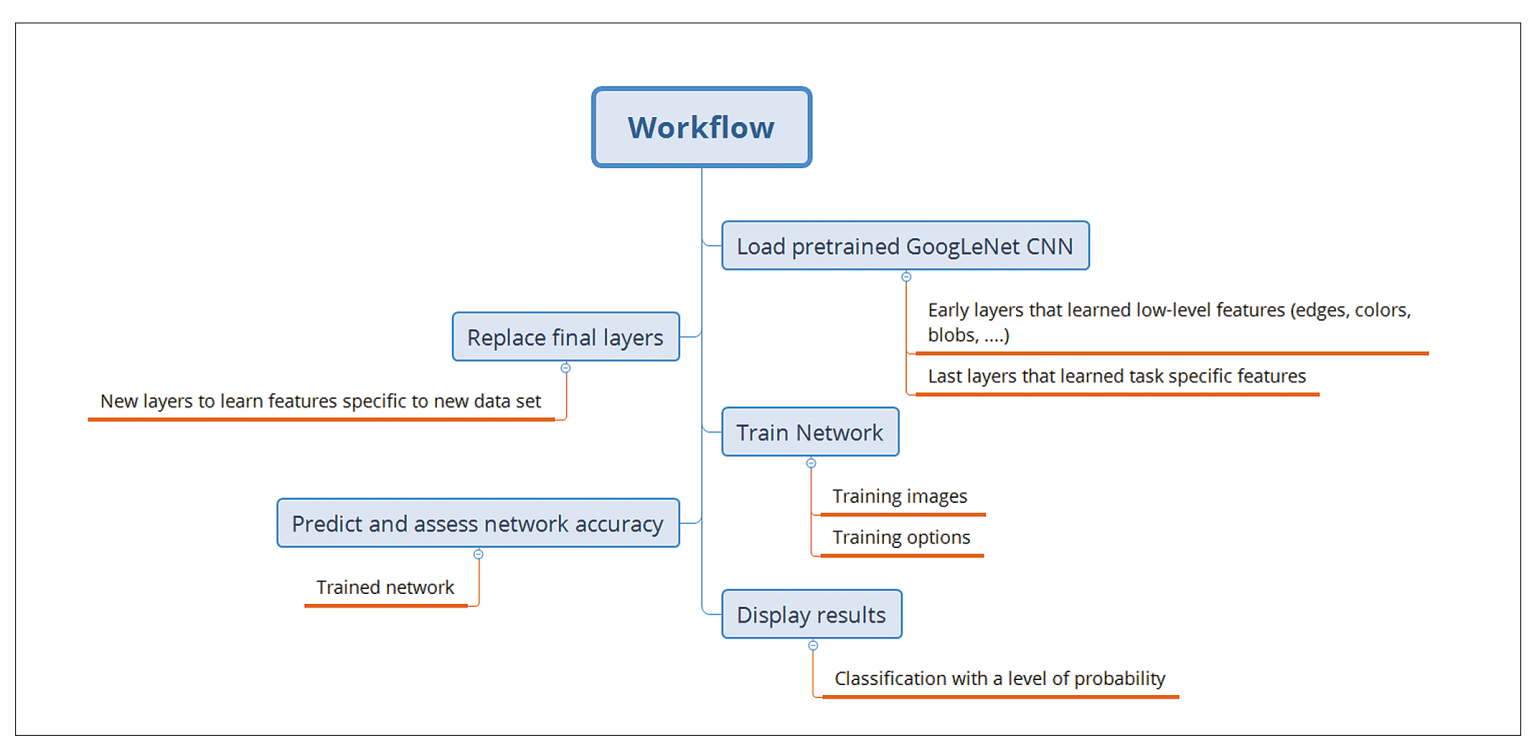

Fig. 3. Diagram of the operation process during retraining of an artificial neural network 
motor yacht, pushed convoy, catamaran, rowing boat, pedalo, scooter, motorboat;

- Z4 - barge, special purpose service ships, motor yacht, passenger ship, sailing yacht;

- Z5 - barge, other, special purpose service ships, kayak, motor yacht, passenger ship, sailing yacht, pushed convoy; - Z6 - barge (with pushed convoy), other, special purpose service ships, kayak, motor yacht, passenger ship, sailing yacht.

Initial testing consisted of variants $\mathrm{W} 1$ to W8 (see Table 1 for variant definitions). This was intended to generally verify the classification options based on GoogLeNet. In this case, network training was carried out on 70\% (arbitrarily assumed value by the authors, resulting from the repeatability of use in Matlab scripts used to train and test artificial neural networks) of the set images for each class; this division was automatic. At this stage, the data structure in collections must be emphasized. The images were clippings from film frames, and often one unit is included in many images [24, 25]. It hould be noted that often during the collection of data, the same vessels floated on the river. This was characteristic of the places that were chosen for data collection. Due to these two aspects of the data, there should be a degree of caution when considering the classification quality results, as the same units may have been in the training and testing set.

The proper testing consisted of variants W9-W11. Here, the sets were manually divided into two, where the training was done on separate images for separate ships, and testing was also carried out on separate ships. In this case, the possibility of the same unit being duplicated in two sets was eliminated.

The details of the development of variants are presented in Figure 4 and Table 1.

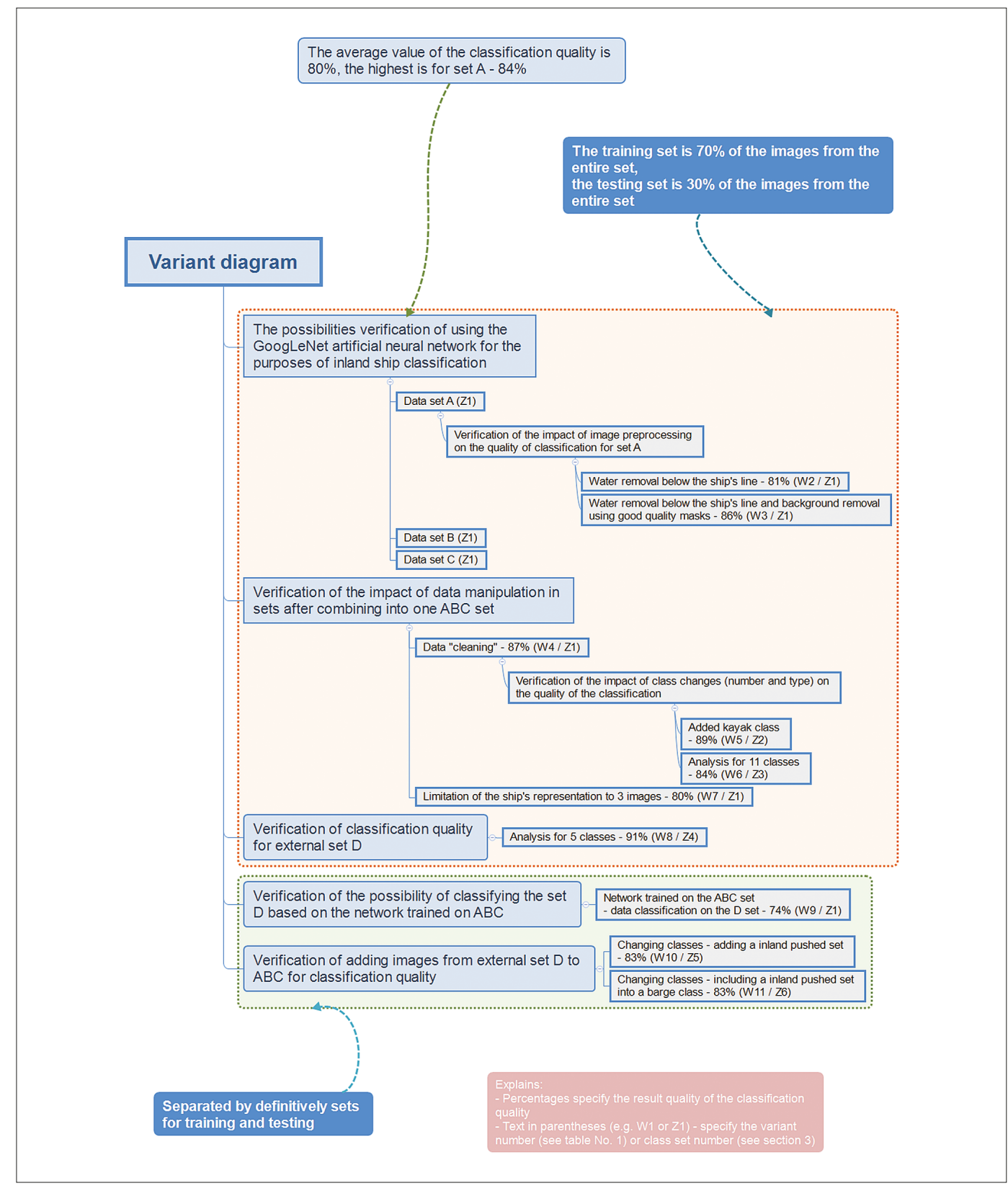

Fig. 4. Variant diagram of the work process of dataset selection 
Tab. 1. Detailed description of the variant

\begin{tabular}{|c|c|c|c|}
\hline Variants & Description & Conclusions & Recommendations for future work \\
\hline W1 & $\begin{array}{l}\text { - analyze primary data; } \\
\text { - divided into three sets A, B and C } \\
\quad \text { (verification for each individual) }\end{array}$ & $\begin{array}{l}\text { - training evaluation and quality of } \\
\text { classification shows the potential of using } \\
\text { GoogLeNet to perform the task }\end{array}$ & $\begin{array}{l}\text { - verification of the impact of image } \\
\text { preprocessing on the quality of } \\
\text { classification; } \\
\text { - verification of the impact of changing the } \\
\text { number of classes on the quality of the } \\
\text { classification }\end{array}$ \\
\hline W2 & $\begin{array}{l}\text { - for set A, the bottom of the image was } \\
\text { limited to the bottom line of the vessel } \\
\text { ("water removal" using the proprietary } \\
\text { algorithm) }\end{array}$ & $\begin{array}{l}\text { - the quality of the classification increased } \\
\text { by } 1 \% \text { compared to W1 (set A), which is } \\
\text { too low }\end{array}$ & - verification of background removal effect \\
\hline W3 & $\begin{array}{l}\text { - for set A, apart from "removing water", } \\
\text { the background was cut out based on } \\
\text { the ship's mask [8][26] }\end{array}$ & $\begin{array}{l}\text { - the quality of the classification increased } \\
\text { by } 1 \% \text { compared to } \mathrm{W} 2 \text {; } \\
\text { - the value is too low compared to the } \\
\text { computational cost to be imposed on the } \\
\text { whole process }\end{array}$ & $\begin{array}{l}\text { - accumulate sets A, B, C into one; } \\
\text { - "clean up data"; } \\
\text { - failure to preprocess image }\end{array}$ \\
\hline W4 & $\begin{array}{l}\text { - train and test the ABCD dataset; } \\
\text { - verify images and remove images from the } \\
\text { collection that badly represent individuals } \\
\text { (no representation of the entire ship, ship } \\
\text { too small, vessel blurred)(Z1) }\end{array}$ & $\begin{array}{l}\text { - increased the quality of the classification; } \\
\text { - a good result, but the images should be } \\
\text { manually divided for testing }\end{array}$ & $\begin{array}{l}\text { - verification of the impact of changes in } \\
\text { the number of classes on the quality of } \\
\text { classification }\end{array}$ \\
\hline W5 & $\begin{array}{l}\text { - separate the kayak class from the other } \\
\text { classes (Z2) }\end{array}$ & $\begin{array}{l}\text { - increased the quality of classification } \\
\text { compared to W4 }\end{array}$ & $\begin{array}{l}\text { - verification of increasing the number of } \\
\text { classes effect on classification quality }\end{array}$ \\
\hline W6 & $\begin{array}{l}\text { - perform training and testing on a set } \\
\text { divided into } 11 \text { classes }(\mathrm{Z} 3)\end{array}$ & $\begin{array}{l}\text { - decreased classification quality compared } \\
\text { to W5; } \\
\text { - the classification error increased for } \\
\text { special purpose service ships, small motor } \\
\text { yacht, large motor yacht and motorboat; } \\
\text { - high quality classification was noted } \\
\text { for the barge and the pushed set, but } \\
\text { unfortunately this resulted from the small } \\
\text { amount of data and the repeatability of } \\
\text { the photos in the training and test set }\end{array}$ & $\begin{array}{l}\text { - it is considered unreasonable to classify } \\
\text { with this number of images the small } \\
\text { motor yacht and large motor yachts }\end{array}$ \\
\hline W7 & $\begin{array}{l}\text { - limit the representation of one ship to } \\
\text { three images in the } Z 1 \text { set }\end{array}$ & - no increase in classification quality & $\begin{array}{l}\text { - abandon this process in further works and } \\
\text { return to the previous number of images }\end{array}$ \\
\hline W8 & $\begin{array}{l}\text { - train and test on a new dataset }(\mathrm{D}) \text {, where } \\
\text { each ship is represented by one image (no } \\
\text { repeatability possible) (Z4) }\end{array}$ & - high quality classification (91\%) & $\begin{array}{l}\text { - verification of entering data from set } \mathrm{D} \text { for } \\
\text { changing the quality of classification; } \\
\text { - dividing image sets for training and } \\
\text { testing so that they are mutually exclusive }\end{array}$ \\
\hline W9 & $\begin{array}{l}\text { - verify the possibility of classifying dataset } \\
\text { D based on a network over-trained on the } \\
\text { ABC dataset }\end{array}$ & $\begin{array}{l}\text { - } 74 \% \text { quality classification; } \\
\text { - rated as good at this stage because of the } \\
\text { completely different image characteristics }\end{array}$ & $\begin{array}{l}\text { - verify entering data from set } \mathrm{D} \text { to } \mathrm{ABC} \text { for } \\
\text { changing the quality of classification }\end{array}$ \\
\hline W10 & $\begin{array}{l}\text { - divide image sets for training and testing } \\
\text { so that they are mutually exclusive } \\
\text { - include set D in training and testing sets } \\
\text { - add an inland pushed set class due to new } \\
\text { data from set D that may represent this } \\
\text { class }\end{array}$ & $\begin{array}{l}\text { - quality classification } 83 \% \text {; } \\
\text { - repeated incorrect classification of the } \\
\text { sailing yacht - this phenomenon occurs } \\
\text { due to the data that the sailing yacht } \\
\text { represents: the sailing yacht is often } \\
\text { represented without a mast or sail (there } \\
\text { is a "cut") and is "confused" with a motor } \\
\text { yacht; } \\
\text { - decreased the quality of the classification } \\
\text { and is also associated with the incorrect } \\
\text { rewriting of kayak and motorboat class } \\
\text { objects as "other" (some blurred objects in } \\
\text { the images may be confused with a rowing } \\
\text { boat, which is part of the class other) }\end{array}$ & $\begin{array}{l}\text { - verify the change of attachment of the set } \\
\text { pushed into the barge; } \\
\text { - work on changing the image database, } \\
\text { refining algorithms for recognizing sailing } \\
\text { yachts and cutting them out of the film } \\
\text { frame with the mast, and obtain better } \\
\text { quality images }\end{array}$ \\
\hline W11 & $\begin{array}{l}\text { - compared to W10, the push set is } \\
\text { includedin the barge class }\end{array}$ & $\begin{array}{l}\text { - the quality of the classification has not } \\
\text { changed significantly compared to W11 }\end{array}$ & - as above \\
\hline
\end{tabular}


Work was completed on the W11 variant because of the conclusions drawn. It was thought that the best option was the trained network from the W11 variant (set Z6), due to the availability of pictures associated with the pushed convoy and the frequency with which this unit occurs on inland waters.

Figure 5 shows the confusion matrix for the W11 variant. It provides numerical values regarding the quality of the classification, giving the numbers of correctly and negatively classified vessels [27]. Examples of correctly classified vessels are presented in Figure 6, while incorrectly classified vessels are shown in Figure 7. These examples confirm that there is a problem with the classification of some yachts, motorboats and kayaks due to their strong similarity with other vessels. In addition to the similarity of the hull of the vessels and incorrect cropping of the image, the authors put forward some hypotheses about the reasons for the misclassification of vessels, which will be the subject of further research. As such, the following can be indicated:

- low image quality (photo resolution less than $224 \times 224$ ) in the test and training set,

- representation of the class in the training set by an insufficient number of differentiated units (with nonstandard characteristics),

- too few photos in the training set,

- problem with a down or invisible mast in the sail yacht class.

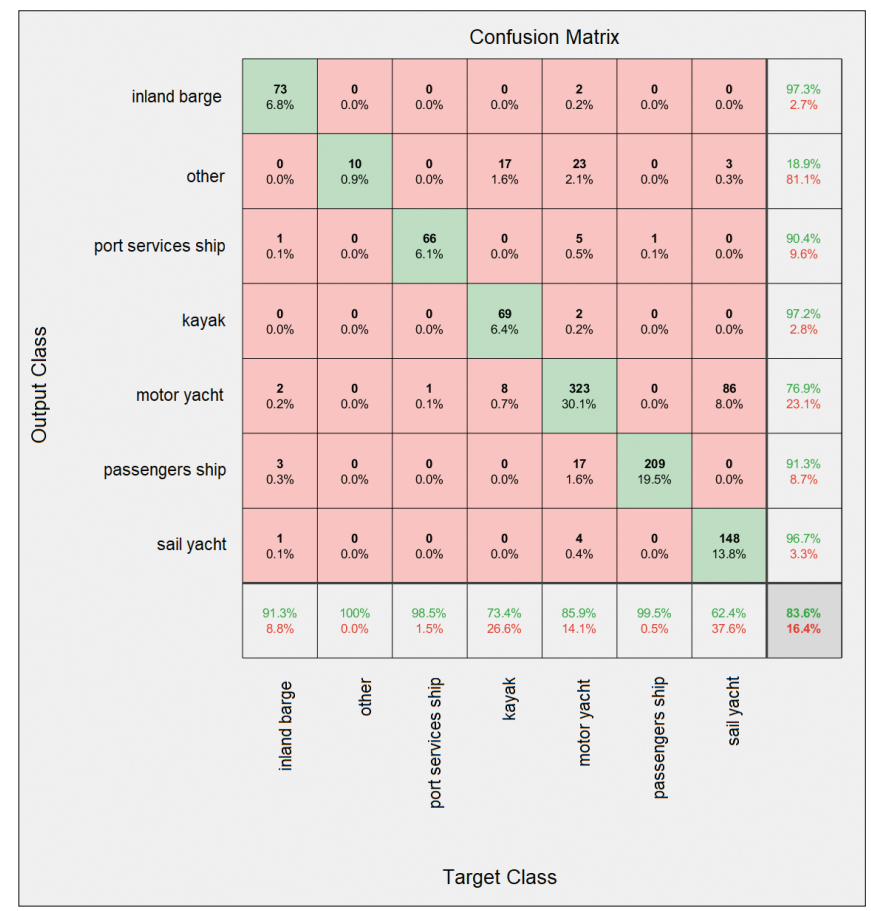

Fig. 5. Confusion matrix for the W11 variant

\section{DISCUSSION AND CONCLUSIONS}

The developed classification algorithm will be one of the key components of the SHREC system. Ship classification will be partly based on the retrained GoogLeNet network. Images representing the inland ships will be the input values. However, the output will take into account the probability

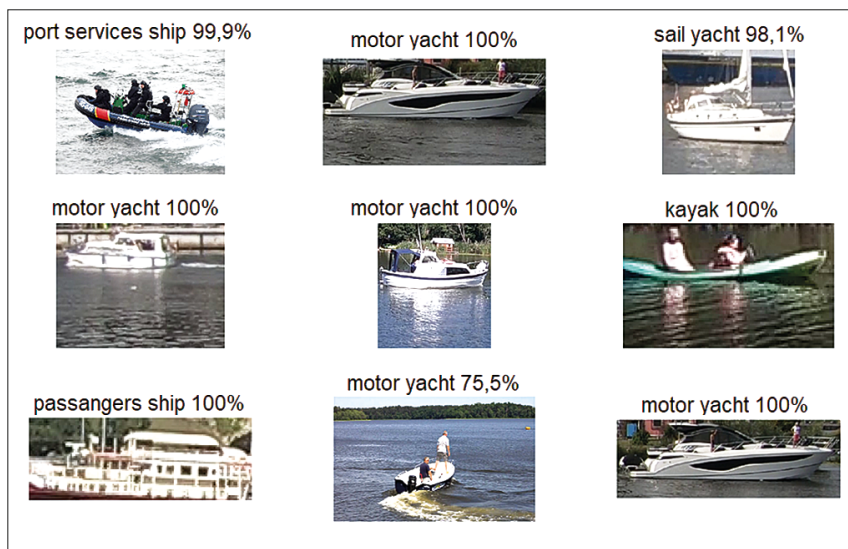

Fig. 6. Examples of correctly classified vessels together with the probability of correct classification assigned to the class

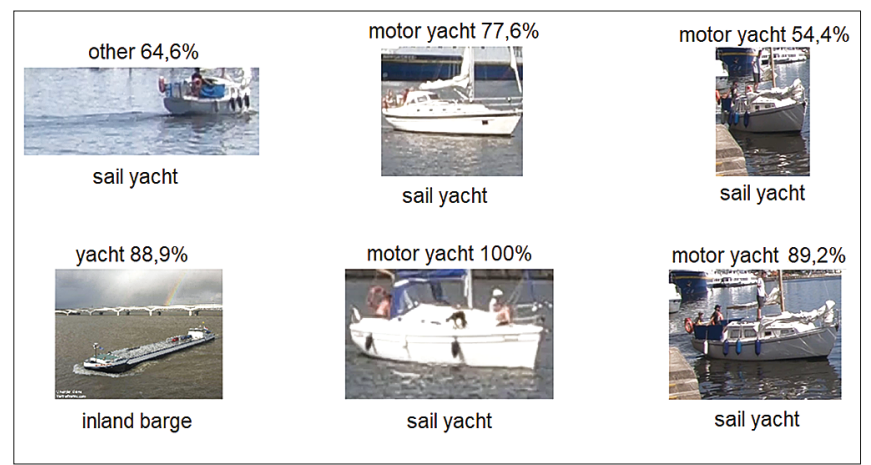

Fig. 7. Examples of incorrectly classified vessels together with the probability of classification for the class

values of assigning a particular class. The entire classification developed in the SHREC system will be complex and based on logical principles. Nevertheless, the data on the probability of the recognized class will be important supporting information toward making the final decision in ship recognition.

For the purposes of achieving the best results in the classification of vessels, it is suggested to develop guidelines for photos constituting the basis for teaching the network. It is obvious that there should be as many images as possible for each category. Pictures for individual categories should be taken in the highest resolution and quality (color images with a resolution of $224 \times 224$ pixels are optimal). It is also important to view the vessel in the largest possible size (in the whole frame) as it allows the valuable details that characterize a given class to be captured. Similarly, it is important to use only those pictures on which the background is minimized, i.e., it is best that the vessel or craft is presented in open water, where the background will be water and sky. It is also crucial to gather a database of vessels without duplicates.

Assuming that the SHREC system will operate on CCTV cameras directed either from the side of the fairway or exactly on its axis, it is necessary to have a database of vessels taking into account the view of the vessel from the boat, stern and each side. Proper classification is influenced by both the shape of the bow or stern, as well as the silhouette of the superstructure or the characteristic elements on the ship's sides. For this purpose, the $45^{\circ}$ angle scheme is recommended. 
For the purposes of unit classification, parallel to the research on the GoogLeNet network, machine learning [28] will be carried out. The future work is in collaboration with machine learning algorithms. It involves the use of both the GoogLeNet network and machine learning, as two components in the classification module. Wherever a given method brings better results, it will be used in another component of the SHREC system - in the identification module. For machine learning purposes, six classes of objects will be used:

1. inland barge - combining inland barges, pushers and pushed sets;

2. motor yacht;

3. sail yacht;

4. passenger ship;

5. port service ships;

6. other - kayak, small boat, pedalo and all other.

GoogLeNet is supposed to be used as a second step in the classification process, wherever it will be possible to divide the class into individual units. A good example is Class 6 (other), where kayaks, small boats, pedalos and catamarans are included.

The goal established at the beginning of the research was achieved. The potential to use the GoogLeNet framework for the purposes of inland ship classification has been proven.

\section{REFERENCES}

1. Wawrzyniak, N.; Stateczny, A. Automatic watercraft recognition and identification on water areas covered by video monitoring as extension for sea and river traffic supervision systems. Polish Marit. Res. 2018, 25, 5-13, doi: 10.2478/pomr-2018-0016.

2. Kanjir, U.; Greidanus, H.; Oštir, K. Vessel detection and classification from spaceborne optical images: A literature survey. Remote Sens. Environ. 2018, 207, 1-26, doi: 10.1016/j. rse.2017.12.033.

3. Bobkowska, K. Analysis of the objects images on the sea using Dempster-Shafer theory. In 2016 17th Int. Radar Symp. (IRS); 2016; pp. 78-81, doi: 10.1109/irs.2016.7497280.

4. Wang, C.; Jiang, S.; Zhang, H.; Wu, F.; Zhang, B. Ship detection for high-resolution SAR images based on feature analysis. IEEE Geosci. Remote Sens. Lett. 2014, 11, 119-123, doi: 10.1109/LGRS.2013.2248118.

5. Stateczny, A. Full implementation of the River Information Services of border and lower section of the Odra in Poland. In 2016 Baltic Geodetic Congress (BGC Geomatics); 2016; pp. 140-146, doi: 10.1109/BGC.Geomatics.2016.33.

6. Shao, Z.; Wang, L.; Wang, Z.; Du, W.; Wu, W. Saliency-aware convolution neural network for ship detection in surveillance video. IEEE Trans. Circuits Syst. Video Technol. 2019, doi: 10.1109/TCSVT.2019.2897980.

7. Wawrzyniak, N.; Hyla, T. Automatic ship identification approach for video surveillance systems. In Proceedings of ICONS 2019 The Fourteenth International Conference on Systems, IARIA, Valencia, Spain; 2019; pp. 65-68.

8. Wawrzyniak, N.; Hyla, T.; Popik, A. Vessel detection and tracking method based on video surveillance. Sensors (Switzerland) 2019, 19, 23, doi: 10.3390/s19235230.

9. Ferreira, J. C.; Branquinho, J.; Ferreira, P. C.; Piedade, F. Computer vision algorithms fishing vessel monitoring Identification of vessel plate number. In International Symposium on Ambient Intelligence; 2017; pp. 9-17.

10. Bobkowska, K.; Wawrzyniak, N. The Hough transform in the classification process of inland ships. Sci. JOURNALS Marit. Univ. SZCZECIN-ZESZYTY Nauk. Akad. MORSKIEJ W SZCZECINIE 2019, 58, 9-15, doi: 10.17402/331.

11. Akiyama, T.; Kobayashi, Y.; Kishigami, J.; Muto, K. CNNbased boat detection model for alert system using surveillance video vamera. In 2018 IEEE 7th Global Conference on Consumer Electronics (GCCE); 2018; pp. 669-670, doi: 10.1109/GCCE.2018.8574704.

12. Zhang, M. M.; Choi, J.; Daniilidis, K.; Wolf, M. T.; Kanan, C. Vais: A dataset for recognizing maritime imagery in the visible and infrared spectrums. In Proceedings of the IEEE Conference on Computer Vision and Pattern Recognition Workshops; 2015; pp. 10-16, doi: 10.1109/CVPRW.2015.7301291.

13. Solmaz, B.; Gundogdu, E.; Yucesoy, V.; Koç, A.; Alatan, A. A. Fine-grained recognition of maritime vessels and land vehicles by deep feature embedding. IET Comput. Vis. 2018, 12, 1121-1132, doi: 10.1049/iet-cvi.2018.5187.

14. Zhong, Z.; Jin, L.; Xie, Z. High performance offline handwritten Chinese character recognition using GoogLeNet and directional feature maps. In 2015 13th International Conference on Document Analysis and Recognition (ICDAR); 2015; pp. 846-850, doi: 10.1109/ICDAR.2015.7333881.

15. Tang, P.; Wang, H.; Kwong, S. G-MS2F: GoogLeNet based multi-stage feature fusion of deep CNN for scene recognition. Neurocomputing 2017, 225, 188-197, doi: 10.1016/j. neucom.2016.11.023.

16. Al-Qizwini, M.; Barjasteh, I.; Al-Qassab, H.; Radha, H. Deep learning algorithm for autonomous driving using GoogLeNet. In 2017 IEEE Intelligent Vehicles Symposium (IV); 2017; pp. 89-96, doi: 10.1109/IVS.2017.7995703.

17. Aswathy, P.; Siddhartha; Mishra, D. Deep GoogLeNet features for visual object tracking. In 2018 IEEE 13th International 
Conference on Industrial and Information Systems (ICIIS); 2018; pp. 60-66, doi: 10.1109/ICIINFS.2018.8721317.

18. Xie, S.; Zheng, X.; Chen, Y.; Xie, L.; Liu, J.; Zhang, Y.; Yan, J.; Zhu, H.; Hu, Y. Artifact removal using improved GoogLeNet for sparse-view CT reconstruction. Sci. Rep. 2018, 8, 6700, doi: 10.1038/s41598-018-25153-w.

19. Wu, C.; Wen, W.; Afzal, T.; Zhang, Y.; Chen, Y. A compact DNN: Approaching GoogLeNet-level accuracy of classification and domain adaptation. In 2017 IEEE Conference on Computer Vision and Pattern Recognition (CVPR); 2017, doi: 10.1109/CVPR.2017.88.

20. Shin, H.; Roth, H.; Gao, M.; Lu, L.; Xu, Z.; Nogues, I.; Yao, J.; Mollura, D.; Summers, R. Deep convolutional neural networks for computer-aided detection: $\mathrm{CNN}$ architectures, dataset characteristics and transfer learning. IEEE Trans. Med. Imaging 2016, 35, doi: 10.1109/TMI.2016.2528162 .

21. Castro, W.; Oblitas, J.; De-La-Torre, M.; Cotrina, C.; Bazán, K.; Avila-George, H. Classification of cape gooseberry fruit according to its level of ripeness using machine learning techniques and different color spaces. IEEE Access 2019, 7, 27389-27400, doi: 10.1109/ACCESS.2019.2898223.

22. Szymak, P. Recognition of underwater objects using deep learning in Matlab. In International Conference on Applied Mathematics \& Computational Science (ICAMCS.NET), 2018, doi: 10.1109/ICAMCS.NET46018.2018.00018.

23. https://www.mathworks.com/help/deeplearning/examples/ train-deep-learning-network-to-classify-new-images.html.

24. Hyla, T.; Wawrzyniak, N. Automatic ship detection on inland waters: Problems and a preliminary solution. In Proceedings of ICONS 2019 The Fourteenth International Con-ference on Systems, IARIA, Valencia, Spain; 2019; pp. 56-60.

25. Popik, A.; Zaniewicz, G.; Wawrzyniak, N. On-water video surveillance: data management for a ship identification system. Zesz. Nauk. Akad. Morskiej w Szczecinie 2019, 60, 56-63, doi: 10.17402/372.

26. Wawrzyniak, N.; Hyla, T. Ships detection on inland waters using video surveillance system. In FIP International Conference on Computer Information Systems and Industrial Management; Springer, Cham, 2019; pp. 39-49, doi: 10.1007/978-3-030-28957-7_4.

27. Tharwat, A. Classification assessment methods. Appl. Comput. Informatics 2018, doi: 10.1016/j.aci.2018.08.003.

28. Wlodarczyk-Sielicka, M.; Polap, D. Automatic Classification Using Machine Learning for Non-Conventional Vessels on Inland Waters. Sensors (Basel). 2019, 19, 3051, doi: 10.3390/ s19143051.

\section{CONTACT WITH THE AUTHORS}

\author{
Katarzyna Bobkowska \\ e-mail: katbobko@pg.edu.pl
}

Gdańsk University of Technology

Narutowicza 11/12

80-233 Gdańsk

Marine Technology Sp. z o.o. ul. Roszczynialskiego 4, lok. 6 81-521 Gdynia Poland

\author{
Izabela Bodus-Olkowska \\ e-mail:i.olkowska@am.szczecin.pl \\ Maritime University of Szczecin \\ ul. Wały Chrobrego 1-2 \\ 70-500 Szczecin \\ Poland
}

